\title{
A mortality and morbidity study of refinery and petrochemical employees in Lovisiana
}

\author{
S P Tsai, J K Wendt, K M Cardarelli, A E Fraser
}

Occup Environ Med 2003;60:627-633

See end of article for authors' affiliations ....................

Correspondence to: Dr S P Tsai, Shell Oil Company, Corporate Health Department, PO Box 2463, Houston, Texas 77252-2463, USA; shan.tsai@shell.com

Accepted

7 November 2002

\begin{abstract}
Aims: To examine the mortality experience of 4221 employees from 1973 to 1999 and the illness absence patterns for 2203 employees from 1990 to 1999 of a chemical and refinery facility in Louisiana.

Methods: Mortality and illness absence data were extracted from the Shell Oil Company's health surveillance system (HSS). The standardised mortality ratio was used as a measure of mortality risk. Morbidity frequency and duration of absence were calculated by age, sex, and four health risk factors (cigarette smoking, high blood pressure, hypercholesterolaemia, and obesity).

Results: Male employees experienced a significant deficit in mortality for all causes of death, all cancers, lung cancer, heart disease, and respiratory disease compared with the corresponding US population. Brain cancer was non-significantly increased, with six observed and five expected deaths; mortality from leukaemia was consistently lower than expected. The majority of employees had no illness absences of six days or longer during the 10 year study period. The loss of productivity (in terms of days of absence) was greater for employees with health risk factors. Ever smoking male employees had a $79 \%$ increase of heart disease and more than $50 \%$ higher rates of respiratory disease and musculoskeletal disorders compared to non-smokers. Smokers were absent 2.9 and 1.6 more days than non-smokers and ex-smokers, respectively.

Conclusions: Regardless of the comparison population, significantly fewer deaths were seen for all causes combined, all cancers, lung cancer, heart disease, or non-malignant respiratory disease. Illness absence rates and duration were higher among employees with health risk factors.
\end{abstract}

$\mathrm{T}$ he study was conducted to assess the health status of employees at a refinery and chemical facility in Louisiana. Over the past 20 years, Louisiana has been a focus of public and state government concerns related to human health effects associated with potential occupational hazards and environmental pollution. The petrochemical industry has been cited as a major pollution source, especially along the Mississippi River of the Industrial Corridor area in southern Louisiana. In 1988, Greenpeace reported that "the devastating excess mortality along the Mississippi River and its significant association with increased levels of toxics warrants great concern, urgent action, and more research". ${ }^{1}$ Since that time, several scientists have conducted research on cancer in Louisiana. ${ }^{2-7}$

The facility, Norco Manufacturing Complex (NMC), which is comprised of a refinery and a chemical plant, is located on the east bank of the Mississippi River, 25 miles upriver from New Orleans. NMC is one of the larger petrochemical manufacturing facilities in the United States, refining in excess of 200000 barrels per day of crude oil and manufacturing various fuels and petrochemicals such as ethylene, propylene, automotive gasoline, jet fuel, heating oil, petroleum coke, epichlorohydrin, calcium chloride, butadiene, catalysts, and epoxy resins. Other potentially hazardous substances found at the facility include hydrogen sulphide, polynuclear aromatics, asbestos, and various solvents. Currently there are approximately 1400 employees at NMC; about half of them are working at the chemical plant and the other half at the refinery. Motiva Enterprises LLC, a joint venture of Shell Oil Company and Saudi Refining, Inc., currently owns the refinery.

The present study evaluated the health status of NMC employees. We sought to determine whether work environment was correlated with mortality/morbidity patterns. This study is divided into two parts. The first describes the mortality experience from 1973 to 1999 of 4221 employees and retirees. The second is an examination of the morbidity (illness absence) experience from 1990 to 1999 for those $(n=2203)$ who ever worked at Norco during this period. The mortality portion of this report is an update of a prospective mortality surveillance study, updated primarily by extending the vital status follow up through 1999. The additional six years of follow up adds substantial statistical power to the original cohort and provides more stable estimates of mortality risks of NMC employees.

\section{MATERIALS AND METHODS \\ Mortality}

Mortality, morbidity, and physical examination data are routinely collected as part of occupational health surveillance programmes at Shell Oil Company in order to detect adverse health effects that may be associated with personal risk factors or occupational hazards. The Shell Health Surveillance System (HSS), established in 1979, contains demographic, mortality, morbidity, physical examination, and work history data. ${ }^{8}$ The mortality study population consisted of 4221 company refinery and chemical employees who worked more than six cumulative months before 31 December 1999, and who were actively employed as of 1 January 1973, or later, and pensioners who were alive as of 1 January 1973. An employee entered the follow up period on 1 January 1973, if he or she began employment at least six months before that date. Otherwise, he/she entered the study six months after the first

Abbreviations: $\mathrm{BMI}$, body mass index; $\mathrm{Cl}$, confidence interval; HSS, health surveillance system; NDI, National Death Index; NMC, Norco Manufacturing Complex; OCMAP, Occupational Cohort Mortality Analysis Program; SIR, standardised incidence ratio; SMR, standardised mortality ratio; SSA, Social Security Administration 


\section{Main messages}

- This study found no increased risk of mortality attributable to employment at this refinery and petrochemical facility The favourable mortality finding is probably due to a combination of the healthy worker effect, the relative absence of risks related to employment at this facility, and the positive socioeconomic effects of continuing employment with its many benefits including greater access to medical care.

- The loss of productivity (in terms of days of absence) was greater for employees with selected health risk factors (smoking, high blood pressure, high cholesterol, and obesity). On an annual average, smokers were absent 2.9 and 1.6 more days than non-smokers and ex-smokers, respectively. Overweight employees were absent one day longer. Employees with high blood pressure were absent 6.2 days compared to 4 days for employees without hypertension. Employees with increased cholesterol also had a longer duration of absence than those with normal cholesterol levels ( 4.5 versus 4.2 days)

\section{Policy implications}

- This study has shown the usefulness of health surveillance data in studying an occupational cohort. Analysis of mortality and morbidity surveillance data can quickly identify areas of concern and be a useful prelude to the design of more specific occupational health studies.

- The findings of this study are useful in setting priorities for medical programmes and directing health promotion efforts and other prevention strategies.

day of employment. Person-years were accumulated from the entry date to the date of death or the study end date, whichever came first.

Vital status as of 31 December 1999 for each employee, including those who terminated employment for reasons other than retirement, was determined from a number of sources. Company records were supplemented with results of a data linkage search with the National Death Index (NDI), which has a demonstrated ability to ascertain $97 \%$ of deaths occurring since $1979 . .^{910}$ Additionally, we performed a data linkage search between company records and the Social Security Administration's (SSA) Master Beneficiary Record file to identify any additional deaths that may have been missed by the NDI. Terminated employees not identified by the NDI search or the SSA search were assumed to be alive. Of those employees who were terminated before the inception of the NDI (1973-78), the average age of the 107 males was 28 years (range 18-54 years), and the average age of the 26 females was 24 years (range 17-38 years). Retiree vital status was also supplemented by records from the company pension benefit plan administrator, which must receive a copy of all death certificates before survivor benefits will be paid. Death certificates were obtained for all but one of the decedents. For each death certificate, the underlying cause of death was coded according to the revision of the International Classification of Diseases (ICD) in effect at the time of death by a trained nosologist.

Mortality excesses and deficits are expressed as standardised mortality ratios (SMRs). The SMR and its $95 \%$ confidence interval (CI) for each cause of death was computed using the Occupational Cohort Mortality Analysis Program (OCMAP). ${ }^{11}$ The SMR is the number of observed deaths in the study group divided by the number of expected deaths. Expected deaths were based on the US general population adjusted for age, race, and calendar time. To help accommodate for geographic variations in mortality, mortality rates for the State of Louisiana and an Industrial Corridor seven-parish region, which were obtained from the Mortality and Population Data System
(MPDS), ${ }^{12}$ were also used for comparison. The Industrial Corridor region consists of the following seven parishes: East Baton Rouge, West Baton Rouge, Iberville, Ascension, St John the Baptist, St James, and St Charles. ${ }^{3}{ }^{13}$ Most Norco employees reside in one of the seven parishes, and the Norco complex is located in St Charles parish.

\section{Morbidity}

The morbidity study population $(\mathrm{n}=2203)$ consisted of all company employees who worked at NMC from 1990 to 1999. This population was dynamic, with employees entering the observation period at different times, and some remaining for less than the entire period.

Morbidity data for this study were extracted from the morbidity section of the HSS, which includes all illness absence events of six work days or longer. Since records of absences originate from personnel and payroll systems, the absence reporting is virtually complete. Seventy five per cent of the morbidity reports had physician statements identifying the reason for the absence. The causes of morbidity were coded according to the ICD 9th Revision Clinical Modification. ${ }^{14}$ Only the primary cause was used in the analysis. Pregnancy and childbirth related absences were excluded.

Data for selected risk factors were also derived from the HSS, which contains all employee pre-placement and periodic examinations done since January 1978. The most current examination data for each employee were used; approximately 95\% of these were completed since 1990. Smoking history from each examination was used to determine whether an employee was a current cigarette smoker. Increased cholesterol was defined as a value equal to or greater than $200 \mathrm{mg} / \mathrm{dl}$. Raised blood pressures were those diastolic blood pressure readings equal to or greater than $90 \mathrm{~mm} \mathrm{Hg}$ or systolic pressure readings equal to or greater than $140 \mathrm{~mm} \mathrm{Hg}$. Obesity was defined as body mass index $(\mathrm{BMI}=$ weight $[$ in $\mathrm{kg}$ ]/height ${ }^{2}$ [in metres]), greater than or equal to 27.2 for men and 26.9 for women. This value represents $20 \%$ more than the ideal body weight based on the National Institutes of Health Consensus Development Panel Recommendations. ${ }^{15}$

The cancer morbidity experience of this population was compared with that of the State of Louisiana. In this comparison, a cancer incidence event was used as the health end point measure. Person-years at risk were calculated for each employee, beginning 1 January 1990, or the date of hire (whichever was later) and ending at the closing date of the study (31 December 1999), the date of retirement, the date of cancer diagnosis, or the date of termination/transfer (whichever was earlier). The expected numbers of cancer incidence cases were calculated from the age and cause specific cancer incidence rates of Louisiana for the years 1993-97. Age standardised incidence ratios (SIRs) for selected cancers were computed as the ratio of the observed to the expected number of new cancer cases during the study period.

\section{RESULTS}

\section{Mortality}

The study cohort included 4221 employees. The average age at entry into the cohort was 34.2 years. The total number of person-years of observation was 78 994; the subjects were followed for an average of 19.2 years for males and 15.8 years for females. Males comprised $85 \%$ of the total population. One third $(33 \%)$ of the population was actively employed by the end of the study period, and retirees $(n=1334)$ accounted for $32 \%$ of the study population. The total number of deaths was 598. Two per cent of the cohort died while employed. Eighty six per cent of the study population was still alive at the end of the study period. Blacks accounted for $12 \%$ of the total population, and whites, $83 \%$. For purposes of statistical analysis, employees whose race could not be determined $(5 \%)$ were included in the "white" category. Overall, more than a third 
Table 1 Observed and expected deaths and SMRs, male Norco employees, 1973-99 (n=3579, person-years $=68881$ )

\begin{tabular}{|c|c|c|c|c|}
\hline Cause of death (8th ICD revision) & Observed & Expected $\dagger$ & SMR & $95 \% \mathrm{Cl}$ \\
\hline All causes of death (001-999) & 580 & 780.3 & $0.74 *$ & 0.68 to 0.81 \\
\hline All malignant neoplasms (140-209) & 152 & 185.8 & $0.82 *$ & 0.69 to 0.96 \\
\hline Digestive organs and peritoneum (150-159) & 41 & 45.5 & 0.90 & 0.65 to 1.22 \\
\hline Stomach (151) & 6 & 5.9 & 1.01 & 0.37 to 2.20 \\
\hline Large intestine (153) & 14 & 16.4 & 0.85 & 0.47 to 1.43 \\
\hline Rectum (154) & 4 & 3.5 & 1.16 & 0.32 to 2.96 \\
\hline Biliary passages and liver primary $(155,156)$ & 2 & 4.5 & 0.44 & 0.05 to 1.59 \\
\hline Pancreas (157) & 12 & 9.0 & 1.34 & 0.69 to 2.34 \\
\hline Respiratory system (160-163) & 46 & 66.2 & $0.70 *$ & 0.51 to 0.93 \\
\hline Bronchus, trachea, lung (162) & 46 & 63.3 & $0.73^{*}$ & 0.53 to 0.97 \\
\hline Prostate (185) & 18 & 17.9 & 1.01 & 0.60 to 1.59 \\
\hline Kidney (189.0, 189.1, 189.2) & 6 & 4.6 & 1.31 & 0.48 to 2.85 \\
\hline Bladder and other urinary organs $(188,189.9)$ & 5 & 5.1 & 0.99 & 0.32 to 2.31 \\
\hline Malignant melanoma of skin (172.0-172.4, 172.6-172.9) & 0 & 3.1 & - & 0.00 to 1.19 \\
\hline Brain $(191,192)$ & 6 & 4.8 & 1.25 & 0.46 to 2.73 \\
\hline All lymphatic and haematopoietic tissue (200-209) & 15 & 18.0 & 0.83 & 0.47 to 1.38 \\
\hline Lymphosarcoma and reticulosarcoma (200) & 3 & 1.3 & 2.32 & 0.48 to 6.79 \\
\hline Hodgkin's disease (201) & 0 & 0.9 & - & 0.00 to 4.24 \\
\hline Leukaemia and aleukaemia (204-207) & 4 & 7.0 & 0.57 & 0.16 to 1.46 \\
\hline All other lymphopoietic tissue $(202-3,208-9)$ & 8 & 8.8 & 0.91 & 0.39 to 1.79 \\
\hline Diabetes mellitus (250) & 16 & 15.2 & 1.13 & 0.65 to 1.83 \\
\hline Cerebrovascular disease (430-438) & 43 & 43.3 & 0.99 & 0.72 to 1.34 \\
\hline All heart disease $(390-8,400.1,400.9,402,404,410-4,420-9)$ & 227 & 274.6 & $0.83^{*}$ & 0.72 to 0.94 \\
\hline Non-malignant respiratory disease (460-519) & 21 & 63.3 & $0.33^{*}$ & 0.21 to 0.51 \\
\hline Cirrhosis of liver (571) & 5 & 15.8 & $0.32 *$ & 0.10 to 0.74 \\
\hline Accidents (800-949) & 30 & 42.4 & 0.71 & 0.48 to 1.01 \\
\hline All other causes of death & 63 & 84.6 & 0.75 & 0.57 to 0.95 \\
\hline
\end{tabular}

(35\%) of the cohort members were hired before 1970, thus having follow up of up to 30 years. Female employees were fairly recent hires. The majority of female employees (60\%) worked less than 10 years at NMC, while about three quarters $(73 \%)$ of the males worked 10 years or longer. The average duration of employment at NMC was 20 years for males and 10 years for females.

Table 1 shows the observed deaths, expected deaths (based on US male mortality rates), SMRs, and their 95\% CIs by selected causes of death for all male employees at Norco. A total of 580 deaths were observed, whereas 780 were expected, with a resultant SMR for all causes of 0.74 (95\% CI 0.68 to $0.81)$. Similarly, there were 152 observed compared with 186 expected cancer deaths ( $\mathrm{SMR}=0.82,95 \%$ CI 0.69 to 0.96 ). Statistically significant deficits in mortality were also observed for: cancer of the respiratory system $(\mathrm{SMR}=0.70,95 \% \mathrm{CI} 0.51$ to 0.93 ), including cancer of the lung ( $\mathrm{SMR}=0.73,95 \% \mathrm{CI}$ 0.53 to 0.97 ); all heart disease (SMR $=0.83,95 \%$ CI 0.72 to $0.94)$; non-malignant respiratory disease ( $\mathrm{SMR}=0.33,95 \% \mathrm{CI}$ 0.21 to 0.51 ); and cirrhosis of the liver ( $\mathrm{SMR}=0.32,95 \% \mathrm{CI}$ 0.10 to 0.74$)$. Fifteen deaths from cancer of all lymphatic and haematopoietic tissue were observed, with 18 expected (SMR $=0.83,95 \%$ CI 0.47 to 1.38 ). There were four deaths from leukaemia (cell types: chronic lymphocytic, acute lymphoblastic, acute myelogenous, and unknown), while seven were expected (SMR $=0.57,95 \%$ CI 0.16 to 1.46 ). Cancer of the brain was slightly increased, but was not statistically significant, based on six observed deaths and 4.8 deaths expected $($ SMR $=1.25,95 \%$ CI 0.46 to 2.73$)$. The observed number of deaths was virtually the same as expected for cancer of the stomach ( 6 observed and 5.9 expected deaths). Cancers of the pancreas (SMR $=1.34,95 \%$ CI 0.69 to 2.34) and kidney $(\mathrm{SMR}=1.31,95 \% \mathrm{CI} 0.48$ to 2.85 ) were nonsignificantly increased. There was a small increase in deaths related to diabetes mellitus ( $\mathrm{SMR}=1.13,95 \% \mathrm{CI} 0.65$ to 1.83 ).

Since detailed exposure histories were not readily available, a subgroup of males with potential plant exposure, including hourly employees and salaried employees who had routine field or laboratory assignments, was also examined. The mor- tality patterns were virtually the same as that seen in the total male cohort in table 1. The SMRs for all causes and all cancers were 0.75 (95\% CI 0.69 to 0.81 ) and 0.80 (95\% CI 0.68 to 0.95 ). The pattern for specific cancer causes did not differ from that of the total group. For example, the SMR was 0.88 ( 5 deaths) for stomach cancer, 1.29 (11 deaths) for pancreas, 0.75 (45 deaths) for lung, 0.98 ( 17 deaths) for prostate, 1.38 (6 deaths) for kidney, 1.33 (6 deaths) for brain, 0.64 (11 deaths) for all lymphatic and haematopoietic tissue, and 0.45 ( 3 deaths) for leukaemia. There were 7 deaths due to non-Hodgkin's lymphoma (ICD code: 200 and 202), with 6.79 deaths expected $(S M R=1.03,95 \%$ CI 0.41 to 2.12$)$. The expected number of deaths for non-Hodgkin's lymphoma was not available from the OCMAP, but was calculated based on the United States mortality rates specific to age, race, and calendar period. ${ }^{16}$ There was only one case of multiple myeloma in this group.

Analysis was also conducted among employees hired since 1950. Results for this more recently employed subgroup were generally similar to the total group, although the SMR for all causes was lower (SMR $=0.62,95 \%$ CI 0.55 to 0.71 ).

Cancers and certain chronic diseases may result after an extended period of occupational exposure. To assess the possible effect of a long duration of employment, a subgroup of male employees $(n=2605)$ with a minimum of 10 years of employment at this facility was also examined (table 2 ). This group contributed $61 \%$ of the person-years for the total cohort. The SMRs were similar to those observed for the total male cohort results. For example, when compared to the USA, mortality for all causes of death combined and for all cancer was significantly lower $(\mathrm{SMR}=0.77$ and $\mathrm{SMR}=0.83$, respectively). The mortality for diabetes mellitus was increased, with 16 observed and 13 expected deaths $($ SMR $=1.23)$.

To examine regional effects on mortality, SMRs were also calculated for this subgroup using mortality rates for the State of Louisiana and the Industrial Corridor area proximate to the Norco complex (table 2). The use of regional rates increased the numbers of expected deaths by $6-11 \%$ for most of the major causes of death, including all cancer and heart disease. 
Table 2 Observed (OBS) and expected (EXP) deaths and SMRs $†$ for selected causes of death for male Norco employees with at least 10 years of employment $(n=2605$, person-years $=42095)$

\begin{tabular}{|c|c|c|c|c|c|c|c|}
\hline \multirow[b]{2}{*}{ Cause of death (8th ICD revision) } & \multirow[b]{2}{*}{ OBS } & \multicolumn{2}{|c|}{ United States } & \multicolumn{2}{|c|}{ Lovisiana } & \multicolumn{2}{|c|}{ Industrial Corridor } \\
\hline & & EXP & SMR & EXP & SMR & EXP & SMR \\
\hline All causes of death (001-999) & 541 & 704.2 & $0.77^{*}$ & 782.1 & $0.69 *$ & 725.1 & $0.75^{*}$ \\
\hline All malignant neoplasms (140-209) & 145 & 174.7 & $0.83^{*}$ & 197.4 & $0.74^{*}$ & 184.3 & $0.79 *$ \\
\hline Digestive organs and peritoneum (150-159) & 40 & 43.0 & 0.93 & 44.2 & 0.91 & 44.0 & 0.91 \\
\hline Stomach (151) & 6 & 5.6 & 1.07 & 5.41 & 1.11 & 5.3 & 1.12 \\
\hline Large intestine (153) & 13 & 15.7 & 0.83 & 15.6 & 0.83 & 16.5 & 0.79 \\
\hline Rectum (154) & 4 & 3.3 & 1.22 & 2.7 & 1.46 & 2.4 & 1.70 \\
\hline Biliary passages and liver primary $(155,156)$ & 2 & 4.2 & 0.47 & 5.1 & 0.39 & 5.1 & 0.39 \\
\hline Pancreas (157) & 12 & 8.5 & 1.41 & 9.9 & 1.21 & 9.7 & 1.24 \\
\hline Respiratory system (160-163) & $4 \overline{4}$ & 63.0 & $0.70^{*}$ & 78.2 & $0.56^{*}$ & 70.4 & $0.63^{*}$ \\
\hline Bronchus, trachea, lung (162) & 44 & 60.3 & $0.73^{*}$ & 75.0 & 0.59 * & 67.5 & 0.65 * \\
\hline Prostate (185) & 18 & 17.6 & 1.02 & 17.7 & 1.02 & 15.3 & 1.17 \\
\hline Kidney $(189.0,189.1,189.2)$ & 5 & 4.3 & 1.17 & 4.7 & 1.06 & 4.7 & 1.07 \\
\hline Bladder and other urinary organs $(188,189.9)$ & 5 & 4.9 & 1.01 & 4.6 & 1.09 & 5.0 & 0.99 \\
\hline Malignant melanoma of skin (172.0-172.4, 172.6-172.9) & 0 & 2.6 & - & 2.4 & - & 2.4 & - \\
\hline Brain $(191,192)$ & 5 & 4.1 & 1.22 & 4.1 & 1.23 & 4.4 & 1.14 \\
\hline All lymphatic and haematopoietic tissue (200-209) & 14 & 16.2 & 0.87 & 17.1 & 0.82 & 17.6 & 0.79 \\
\hline Leukaemia and aleukaemia (204-207) & 3 & 6.3 & 0.48 & 6.8 & 0.44 & 7.0 & 0.43 \\
\hline Diabetes mellitus (250) & 16 & 13.1 & 1.23 & 17.2 & 0.93 & 15.8 & 1.01 \\
\hline Cerebrovascular disease (430-438) & 43 & 41.6 & 1.03 & 46.6 & 0.92 & 38.3 & 1.12 \\
\hline $\begin{array}{l}\text { All heart disease }(390-8,400.1,400.9,402,404,410-4 \text {, } \\
420-9)\end{array}$ & 220 & 261.7 & $0.84^{*}$ & 290.7 & $0.76^{*}$ & 282.9 & $0.78^{*}$ \\
\hline Non-malignant respiratory disease $(460-519)$ & 21 & 60.9 & $0.35^{*}$ & 60.2 & $0.35^{*}$ & 52.8 & $0.40^{*}$ \\
\hline Cirrhosis of liver (571) & 4 & 13.3 & $0.30 *$ & 11.7 & $0.34^{*}$ & 9.1 & 0.44 \\
\hline Accidents (800-949) & 18 & 26.0 & 0.69 & 31.8 & $0.57^{*}$ & 27.1 & 0.67 \\
\hline All other causes of death & 60 & 75.6 & 0.79 & 83.2 & $0.72 *$ & 76.4 & 0.79 \\
\hline
\end{tabular}

The expected numbers of death from lung cancer (75.0 and 67.5) based on the State and Industrial Corridor rates were $24 \%$ and $12 \%$ greater than that of the USA (60.3), reflecting a generally higher mortality in Louisiana for this cancer during the study period. Similar patterns were also noted for pancreas cancer and diabetes mellitus, resulting in lower SMRs for these diseases when the State or Industrial Corridor rates were used as the comparison. Deaths from leukaemia were consistently lower than expected, regardless of which comparison population was used. Mortality from cancer of the brain was slightly increased in all three comparisons (five observed and four expected deaths), but this finding was not statistically significant.

Three deaths with mesothelioma mentioned on the death certificate were identified by reviewing all death certificates. The expected number of deaths cannot be estimated directly because mortality rates in the general population are not available for this cause of death. Using mesothelioma incidence rates for 1973-91 from the Surveillance, Epidemiology, and End-Results (SEER) Program of the National Cancer Institute (unpublished data), 1.39 expected deaths were estimated, resulting in an increased but not statistically significant SMR of 2.16 (95\% CI 0.44 to 6.30 ).

Only 18 deaths occurred among 642 female employees in the study cohort, while 25 deaths were expected, resulting in an SMR of 0.72 (95\% CI 0.42 to 1.13). Seven cancer deaths were observed while 7.6 were expected $(\mathrm{SMR}=0.93,95 \% \mathrm{CI}$ 0.37 to 1.91$)$. Sites of cancer for the seven cancer deaths were lung $(n=2)$, breast $(n=2)$, ovary $(n=1)$, central nervous system $(\mathrm{n}=1)$, and thyroid $(\mathrm{n}=1)$.

\section{Morbidity}

Of the 2203 employees included in the study, 961 (44\%) had at least one illness absence in excess of five days during the 10 year period. Overall, 15\% of the employees (including 16\% of males and $7 \%$ of females) had three or more absences, which accounted for two thirds $(64 \%)$ of the total number of absences and three quarters $(76 \%)$ of the total workdays lost. Female employees $(n=389)$ were an average of 8.7 years younger than males, and their average duration of employment at Norco was 8.5 years less than that of males.

A total of 2476 episodes of absence were reported during the 10 year study period (table 3), with 70259 workdays lost, due to illness absence events in excess of five days (an average of 7026 days per year). This was equivalent to the absence from work of $2.2 \%$ of the average workforce (about 31 employees) each year at NMC during the study period, compared to $2.5 \%$ for all Shell manufacturing employees. This represents only $75 \%$ of the total days of absence since the study only included absences of six days or more. The frequency rates for morbidity generally increased with age, ranging from 7 absences per 100 person-years for those less than 30 years old to 30 absences per 100 person-years for those 60 and older. Female employees had similar rates to males for all age groups, except those aged $60+$ where their rate was substantially lower than the male rate. The average duration of absence also increased with age, and was about the same for female and male employees ( 4.7 days per person versus 4.4 days per person annually). The $60+$ years age group showed the greatest gender difference for average duration of absence (females 1.2 days, males 12.6 days).

Table 4 presents the number of episodes and the average duration of absence per episode by diagnosis and gender. Excluding symptoms and ill defined conditions, the five most common causes of illness absence among male employees were musculoskeletal disorders (19\%), injuries (15\%), respiratory diseases $(12 \%)$, digestive illnesses $(7 \%)$, and circulatory system illnesses $(5 \%)$. For female employees, the most common causes of illness absence were respiratory illnesses $(15 \%)$, genitourinary illnesses $(11 \%)$, musculoskeletal disorders $(9 \%)$, mental disorders $(7 \%)$, and injuries $(6 \%)$.

To compare the morbidity experience of Norco employees with that of all Shell manufacturing employees, standardised (age adjusted) morbidity ratios (SMbRs) were calculated. ${ }^{17} 18$ Overall, Norco males exhibited a $7 \%$ greater morbidity rate than the referent Shell group (1627 illnesses expected and 1514 observed). No disease specific SMbRs were statistically significant. However, the number of observed episodes of 
Table 3 Morbidity episodes, frequency rates*, and average duration of absences in days by age and gender, 1990-99, Norco plant

\begin{tabular}{|c|c|c|c|c|c|c|c|c|c|}
\hline \multirow[b]{2}{*}{ Age } & \multicolumn{3}{|l|}{ Females } & \multicolumn{3}{|l|}{ Males } & \multicolumn{3}{|l|}{ Total } \\
\hline & Episodes & Freq rate & $\begin{array}{l}\text { Average } \\
\text { duration }\end{array}$ & Episodes & Freq rate & $\begin{array}{l}\text { Average } \\
\text { duration }\end{array}$ & Episodes & Freq rate & $\begin{array}{l}\text { Average } \\
\text { duration }\end{array}$ \\
\hline$<30$ & 16 & 5.9 & 1.4 & 63 & 7.4 & 1.2 & 79 & 7.0 & 1.2 \\
\hline 30-39 & 107 & 15.5 & 4.9 & 554 & 13.3 & 3.4 & 661 & 13.6 & 3.6 \\
\hline $40-49$ & 120 & 16.8 & 4.5 & 897 & 14.9 & 3.4 & 1017 & 15.1 & 3.5 \\
\hline $50-59$ & 56 & 25.7 & 9.7 & 535 & 22.8 & 8.8 & 591 & 23.0 & 8.9 \\
\hline $60+$ & 3 & 7.9 & 1.2 & 125 & 31.8 & 12.6 & 128 & 29.7 & 11.6 \\
\hline Total & 302 & 15.6 & 4.7 & 2174 & 15.8 & 4.4 & 2476 & 15.8 & 4.5 \\
\hline
\end{tabular}

Table 4 Number of morbidity episodes and average duration of absence per episode by gender and diagnosis, 1990-99, Norco plant

\begin{tabular}{|c|c|c|c|c|c|c|}
\hline \multirow[b]{2}{*}{ Cause of morbidity (ICD-CM 9th rev. codes) } & \multicolumn{3}{|c|}{ Females } & \multicolumn{3}{|l|}{ Males } \\
\hline & $\mathrm{n}$ & $\%$ & $\begin{array}{l}\text { Average } \\
\text { duration }\end{array}$ & $\mathrm{n}$ & $\%$ & $\begin{array}{l}\text { Average } \\
\text { duration }\end{array}$ \\
\hline Infectious and parasitic diseases (000-139) & 6 & 2.0 & 38.0 & 34 & 1.6 & 11.4 \\
\hline Malignant neoplasms (140-208) & 10 & 3.3 & 98.4 & 36 & 1.7 & 74.9 \\
\hline Benign and other neoplasms (210-239) & 9 & 3.0 & 28.1 & 14 & 0.6 & 29.8 \\
\hline Endocrine and metabolic disease (240-279) & 2 & 0.7 & 10.0 & 34 & 1.6 & 31.5 \\
\hline Mental disorders (290-279) & 22 & 7.3 & 57.3 & 79 & 3.6 & 44.4 \\
\hline Nervous system (320-389) & 15 & 5.0 & 31.6 & 91 & 4.2 & 42.9 \\
\hline Circulatory system (390-459) & 2 & 0.7 & 23.5 & 102 & 4.7 & 55.5 \\
\hline Respiratory system (460-519) & $4 \overline{5}$ & 14.9 & 31.2 & 253 & 11.7 & 10.5 \\
\hline Digestive system (520-579) & 17 & 5.6 & 15.0 & 148 & 6.8 & 17.8 \\
\hline Genitourinary system (580-629) & 34 & 11.3 & 28.6 & 67 & 3.1 & 46.5 \\
\hline Skin and subcutaneous tissue (680-709) & 2 & 0.7 & 23.0 & 38 & 1.8 & 11.9 \\
\hline Musculoskeletal (710-739) & 28 & 9.3 & 48.1 & 404 & 18.6 & 40.9 \\
\hline Symptoms and ill defined conditions (780-799) & 89 & 29.5 & 16.6 & 533 & 24.6 & 18.5 \\
\hline Injury and poisoning (800-999) & 18 & 6.0 & 18.3 & 330 & 15.2 & 23.9 \\
\hline Unknown and all other causes & 3 & 1.0 & 24.0 & 8 & 0.4 & 33.9 \\
\hline All causes (000-999) & 302 & 100.3 & 30.4 & 2171 & 100.2 & 28.1 \\
\hline
\end{tabular}

musculoskeletal disorders and of endocrine system diseases (primarily diabetes) were notably higher than expected (observed versus expected: 264 versus 233, and 27 versus 20, respectively). For females, morbidity at Norco was $4 \%$ lower than that for Shell females overall (218 expected versus 228 observed). There were eight observed cancer cases (two lung, one thyroid, one breast, one colon, one tongue, one cervix, and one ovary) at Norco, with five expected. This difference was not statistically significant, and six of the eight cancer cases were employed as office assistants.

Employees with selected health risk factors had higher overall morbidity frequency rates than those without such risk factors. Illness absence rates were higher for employees with high blood pressure (19.5 versus 15.2 per 100 employees, respectively), with hypercholesterolaemia (16.8 versus 15.1) and for those who were obese (17.9 versus 13.4). The impact of cigarette smoking on the illness absence rate is particularly striking: rates for smokers, ex-smokers, and non-smokers were $20.9,18.6$, and 12.2 per 100 employees, respectively.

The average duration of absences (in days per person) also varied by the presence or absence of health risk factors. Employees who smoked or were obese were absent about three and one day(s) longer, respectively, than those without these risk factors (smoking: 6.4 versus 3.5 days; obesity: 4.9 versus 3.9 days). A similar pattern was seen with high blood pressure ( 6.2 days versus 4.0 days). Employees with hypercholesterolaemia had a slightly longer absence duration than those with normal cholesterol readings (4.5 versus 4.2 days).

A further examination of smoking and obesity showed that these factors increased the risk of some common disease categories. Ever smoking males at Norco had a 79\% increase of heart disease compared to non-smokers ( $0.9 \%$ versus $0.5 \%)$. Ever smoking males also had higher rates of respiratory disease and musculoskeletal disorders than non-smoking males $(2.1 \%$ versus $1.3 \%$ and $3.9 \%$ versus $2.2 \%$, respectively). Musculoskeletal disorders and heart disease were also higher among obese men (musculoskeletal disorders: 3.3\% versus $2.4 \%$; heart disease: $0.9 \%$ versus $0.4 \%$ ). Mental disorders were 2.3 times higher among obese females ( $1.8 \%$ versus $0.8 \%$ ).

During the 10 year study period, no illness absences from brain cancer or pancreatic cancer were observed. Among male employees, eight cases of newly diagnosed prostate cancer were reported. Using prostate cancer incidence rates for the State of Louisiana yielded 6.21 expected cases $($ SIR $=1.29$, $95 \%$ CI 0.56 to 2.54 ). No common jobs were observed among these prostate cancer cases; job titles were purchasing assistant, engineering foreman, chemist, machinist, inspector, coking-hydroprocessing operator, pipefitter, and project coordinator. No increases of other specific cancer sites were noted. For example, the observed cases of newly reported cancers for lung, leukaemia, and lymphoma among male employees were lower than expected ( 5 versus 7.71 , 1 versus 1.23 , and 2 versus 3.06, respectively). Six malignant neoplasms were observed among females. The cases included lung cancer $(n=2)$, breast cancer $(n=1)$, colon cancer $(n=1)$, cervical squamous cell carcinoma $(\mathrm{n}=1)$, and carcinoma of the tongue $(\mathrm{n}=1)$. Job titles for the lung cancer cases were operator and office assistant, respectively.

\section{DISCUSSION}

This study examined the mortality and morbidity experience of NMC employees in Louisiana. The favourable mortality 
experience of this cohort is comparable to what has been reported in other large petroleum and petrochemical populations. ${ }^{19} 20$ The lower overall mortality can be translated into longer life expectancy. ${ }^{21}$ Based on the mortality experience of either the total group or those who worked 10 years or more, the life expectancy at age 25 is estimated to be 3.2 years longer than the general US population. The magnitude of this relative advantage is equivalent to the potential gain in life expectancy if all cancers were eliminated as a cause of death in the US male population. ${ }^{22}$

The favourable mortality findings and better life expectancy experienced by these employees is probably due to a combination of the "healthy worker effect", ${ }^{23-26}$ the relative absence of risks related to employment, and the positive socioeconomic effects of continuing employment with its many benefits including greater access to medical care. While it is difficult to quantify the impact of the healthy worker effect, studies have shown that the healthy worker effect decreased with length of time since entry into the study and generally disappeared after 15 years of follow up. ${ }^{27}$ The selection for "employability" (that is, fitness for duty) by the employer or self selection by the employee is probably the most significant factor for the healthy worker effect, and the impact of this selection is greater among employees with a short duration of employment. The selection process also tends to result in larger socioeconomic class differentials between the employed (with better qualifications) and unemployed (with poorer qualifications). To minimise the potential effect of the healthy worker effect in this study, a subgroup of male employees who worked for 10 years or longer was also examined. Mortality for all causes and all cancer of this group was similar to that of the total male cohort.

Although lung cancer mortality has been historically high among white men in Louisiana for several decades, ${ }^{28}$ there was a significantly decreased lung cancer death rate for the NMC population. In addition, there was no increased leukaemia mortality at this facility. Increased brain cancer mortality among chemical plant employees in Louisiana has been reported. ${ }^{57}$ In this study, the number of observed brain cancer cases was approximately the same as expected among male employees ( 6 versus 5 in the total male cohort, and 5 versus 4 among those working 10 or more years). Two of the cases had spent the majority of their work careers at the chemical plant, and four of the cases worked primarily at the refinery. A review of work histories for the brain cancer cases revealed no predominant pattern of job type or process operation. The average age at death for the brain cancer cases was 54 years, and the average duration of employment was 26 years (range 5-34 years). There were no new mesothelioma deaths found during the update period.

The sample size of this study for either all employees or potentially exposed employees is more than adequate to detect a $22 \%$ increase in mortality for all cancer, given a type I error of 0.05 and type II error of 0.20 . Further, the sample size for the potentially exposed employees was able to detect a twofold increase in pancreas cancer, a $40 \%$ increase in lung cancer, an $80 \%$ increase in prostate and all lymphatic and haematopoietic tissue, and approximately a 2.5 -fold increase of brain cancer and leukaemia, if they had existed.

The morbidity analyses of this study revealed that the small percentage of employees with three or more absences over the 10 year period had a disproportionately large impact on the frequency and severity of morbidity. As expected, illness absence rates increased with increasing age. Similar observations have been noted by other researchers. ${ }^{29}{ }^{30}$ The rates for older male workers ( 60 years and older) were fourfold those of younger males (less than 30 years of age). Similarly, average duration of absence was substantially longer among older employees $(50+$ years) than those less than 50 years of age.

No statistically significant excess of newly diagnosed malignant neoplasms during the 10 years from 1990 to 1999 was found for any cancer site. The increased prostate cancer morbidity ( 8 observed versus 6.21 expected) could be due to early detection of this disease through the company's prostate cancer screening programme, initiated in 1993 at Norco as a part of the routine physical examination. In fact, four of the eight cases were identified as the result of the screening programme (three by positive PSA test and one through physical examination). Among the other four cases, one refused the rectal examination, one did not participate in the physical examination, one developed prostate cancer while on long term disability for peripheral vascular disease, and one developed the cancer between two physical examinations (1990 and 1993).

The health surveillance system does not include employees who died before 1 January 1973. The potential impact of excluding these subjects is not clear and could not be evaluated based on the available data for this study population. Because the cohort includes retirees known to be alive as of 1 January 1973, it could be argued that including these healthier long term survivors could dilute the observed mortality, particularly for cancer with shorter latency. To assess whether cancer of short latency was underestimated, additional analysis was conducted by excluding employees who retired and were alive as of 1 January 1973. Mortality for all causes ( $\mathrm{SMR}=0.64,95 \%$ CI 0.57 to 0.71 ) was significantly lower than the total male cohort. The SMRs for all cancer combined (SMR 0.87, 116 observed deaths) as well as for specific cancers were generally similar to the overall group, for example, stomach (SMR $=1.00,4$ deaths $)$, pancreas $($ SMR $=$ $1.09,7$ deaths), lung ( $S M R=0.79,38$ deaths), prostate (SMR $=1.29,12$ deaths), brain (SMR $=1.45,6$ deaths), all lymphatic and haematopoietic tissue (SMR $=0.90,12$ deaths), and leukaemia (SMR $=0.60,3$ deaths). It is not unexpected that the SMR for all heart disease was low (SMR $=0.69,95 \%$ CI 0.57 to 0.83 ) which contributed to the lower overall mortality for this group. While it may have been informative to display morbidity and mortality rates stratified by personal exposure status, such data were not readily available for this surveillance study. The Norco manufacturing site does have an ongoing industrial hygiene monitoring programme for potentially hazardous agents. Monitoring is conducted for both key products and other materials used in connection with the manufacturing processes, and covers normal operations, maintenance, and special operations. Recent industrial hygiene monitoring data for NMC included 2806 personal samples for benzene. The measurements ranged from $<0.001 \mathrm{ppm}$ to $27.8 \mathrm{ppm}$, with $99 \%$ of the results below $1.0 \mathrm{ppm}$. The average was less than $0.1 \mathrm{ppm}$ (standard deviation $1.0 \mathrm{ppm}$ ). It should be noted that the monitoring results represent potential rather than actual exposure when respiratory protection is worn, as is the case for certain work tasks with potential for significant exposure.

Illness absence in a working population is a complex phenomenon involving many factors. Personal characteristics related to morbidity frequency include age, gender, lifestyle, diet, alcohol use, smoking habits, and occupational factors. In this study, we found that persons with health risk factors such as smoking, increased blood pressure, raised cholesterol values, or obesity, had higher illness absence rates and/or duration of absences. These factors have been associated with increased morbidity. ${ }^{31-34}$

This study shows that certain subgroups of employees in this plant are more likely to experience illness absence events. Clearly, those individuals who have had more than one illness absence represent a group at high risk for additional episodes. Our ultimate goal is to develop medical strategies to maximise good health in employees and to minimise both the frequency and duration of illness absences. Careful return to work evaluations and promotion of smoking cessation, weight reduction, and blood pressure and cholesterol control for employees with multiple absences could produce long term 
dividends. Prostate cancer screening, implemented at NMC in 1993, could have an impact on future prostate cancer mortality by providing early detection and allowing effective early treatment.

We will continue to monitor employee health by analysing mortality and morbidity surveillance data. By working closely with location staff, we can design customised studies to answer questions more definitively about employees' health and its relation to other occupational or non-occupational factors.

\section{Authors' affiliations}

S P Tsai, J K Wendt, K M Cardarelli, A E Fraser, Shell Oil Company,

Corporate Health Department, Houston, Texas

\section{REFERENCES}

1 Public Data Access, Inc. Mortality and toxics along the Mississippi River-a Greenpeace report. Public Data Access, Inc. September 1988.

2 Chen VW, Fontham E, Groves FD, et al. Cancer incidence in South Lovisiana 1983-1986. New Orleans: LSU Medical Center, 1991.

3 Wu XC, Correa CN, Andrews PA, et al. Cancer incidence and mortality in Lovisiana 1993-1997. New Orleans: Louisiana Tumor Registry, 2001.

4 Wong O, Foliart D. Epidemiology factors of cancer in Louisiana. J Environ Pathol Toxicol Oncol 1993;12:171-83.

5 Olsen GW, Kusch GD, Stafford BA, et al. The mortality experience of Dow Chemical Louisiana Division employees, 1956-1986. J La State Med Soc 1992;144:529-32.

6 Tsai SP, Gilstrap EL, Colangelo TR, et al. A mortality study of oil refinery and petrochemical employees. J Occup Environ Med 1997;39:448-54.

7 Ott MG. Mortality experience among Louisiana chemical manufacturing employees, 1957-1992. J La State Med Soc 1996;148:260-6.

8 Joyner RE, Pack PH. The Shell Oil Company's computerized health surveillance system. J Occup Med 1982;24:812-14.

9 Cowper DC, Kubal JD, Maynard C, et al. A primer and comparative review of major US mortality databases. Ann Epidemiol 2002; 12:462-8

10 Acquavella JF, Donaleski D, Hanis NM. An analysis of mortality follow-up through the National Death Index for a cohort of refinery and petrochemical workers. Am J Ind Med 1986;9:181-7.

11 Marsh GM, Preininger M. OCMAP: a user-oriented occupational cohort mortality analysis program. Am Stat 1980;34:245.

12 Marsh GM, Ehland J, Sefcik S. Mortality and Population Data System (MPDS). University of Pittsburgh, Department of Biostatistics. Technical Report, 1987.

13 Chen VW, Andrews PA, Wu XC, et al. Cancer incidence in the Industrial Corridor: an update. J La State Med Soc 1998;150: 158-67.
14 ICD. International Classification of Diseases, 9th revision, Clinical Modification. Ann Arbor, Michigan: Commission on Professional and Hospital Activities, 1978

15 National Institutes of Health, Consensus Development Panel on the Health Implications of Obesity. Health implications of obesity: National Institutes of Health consensus development conference statement. Ann Intern Med 1985;103:1073-7.

16 National Center for Health Statistics. Compressed mortality file 1979-1998. Available from: URL: http://wonder.cdc.gov/ mortlCD9J.shtml.

17 Tsai S, Dowd CM, Cowles SR, et al. Morbidity patterns among employees at a petroleum refinery. J Occup Med 1991;33:1076-80.

18 Tsai S, Dowd CM, Cowles SR, et al. A prospective study of morbidity patterns in a petroleum refinery and chemical plant. $\mathrm{Br} J$ Ind Med 1992:49:516-22

19 Delzell E, Austin H, Cole P. Epidemiologic studies of the petroleum industry. Occup Med 1988;3:455-74.

20 Wong O, Raabe GK. A critical review of cancer epidemiology in the petroleum industry, with a meta-analysis of a combined database of more than 350,000 workers. Regul Toxicol Pharmacol 2000;32:78-98.

21 Tsai SP, Hardy RJ, Wen CP. The standardized mortality ratio and life expectancy. Am J Epidemiol 1992;135:824-31.

22 National Center for Health Statistics. United States life tables eliminating certain causes of death. US decennial life tables for 1979-1981. Vol. 1, No. 2. DHHS Publication No. (PHS) 88-1150-2. Washington, DC: Government Printing Office, July 1988

23 Fox AJ, Collier PF. Low mortality rates in industrial cohort studies due to selection for work and survival in the industry. Br J Prev Soc Med 1976; 30:225-30

24 Ott MG, Holder BB, Langner RR. Determinants of mortality in an industrial population. J Occup Med 1976;18:171-7.

25 Wen CP, Tsai SP, Gibson RL. Anatomy of the healthy worker effect: a critical review. J Occup Med 1983;25:283-9.

26 Monson RR. Observations on the healthy worker effect. J Occup Med 1986;28:425-33.

27 Checkoway H, Pearce NE, Crawford-Brown DJ. Research methods in occupational epidemiology. New York: Oxford University Press, 1989

28 Wong O, Foliart D. Final report. A review of cancer epidemiology in Louisiana. Alameda, CA: ENSR Health Sciences, 1989.

29 Taylor PJ. Occupational and regional associations of death, disablement, and sickness absence among Post Office staff 1972-75. Br $J$ Ind Med 1976:33:230-5.

30 Chevalier A, Luce D, Blanc C, et al. Sickness absence at the French National Electric and Gas Company. Br J Ind Med 1987;44:101-10.

31 US Department of Health, Education and Welfare. Smoking and health. A report of the Surgeon General. PHS publication no. 70-50066. Washington, DC: US Government Printing Office, 1979.

32 Doll R. Smoking and disease: prospects for control. R Soc Health J 1977;97:167-76.

33 Kral JG. Morbid obesity and related health risks. Ann Intern Med 1985;103:1043-7.

34 Fielding JE. Health promotion and disease prevention at the worksite. Annu Rev Public Health 1984;5:237-65.

Answers to multiple choice questions on Surveillance in occupational health by D Koh and T-C Aw, on pages $705-710$

(1) (a) false; (b) false; (c) true; (d) true; (e) true

(2) (a) true; (b) false; (c) true; (d) true; (e) true

(3) (a) false; (b) false; (c) true; (d) false; (e) false

(4) (a) false; (b) true; (c) true; (d) true; (e) false 